\title{
Drug Therapy for Advanced-Stage Liver Cancer
}

\author{
Markus Peck-Radosavljevic \\ Department of Gastroenterology and Hepatology, AKH and Medical University of Vienna, \\ Vienna, Austria
}

\author{
Key Words \\ BCLC $\cdot$ Cirrhosis $\cdot$ Hepatocellular carcinoma $\cdot$ Sorafenib
}

\begin{abstract}
Liver cancer was traditionally treated by surgery or interventional ablative treatments, or, if these options were not feasible, by best supportive care. Since 2008, systemic therapy with the multikinase inhibitor sorafenib has become available worldwide and has become the standard of care for unresectable/non-ablatable or advanced-stage hepatocellular carcinoma (HCC). Sorafenib is able to improve the median overall survival by approximately 3 months. Despite this significant advance in the non-surgical/non-interventional management of liver cancer, this improvement in overall survival is only a first step toward more potent, more targeted, and better tolerated oral antitumor treatments. Since the introduction of sorafenib into clinical practice, several attempts have been made to develop even more effective first-line treatments as well as an effective second-line treatment for HCC. None of these endeavors has been successful so far. The development of drug treatments for HCC has been particularly hampered by the unfortunate push to establish the diagnosis of liver cancer by non-invasive imaging alone, without requiring a liver biopsy for histologic confirmation: this precluded the very necessary search for informative biomarkers and the search for molecular targets for drug development in HCC. This important drawback is being increasingly recognized and corrected. Despite several obstacles remaining to be overcome, it seems reasonable to assume that using a rational, data-driven approach, we will be able to develop better drug treatments for liver cancer in the coming years. $\quad$ Copyright $\odot 2014$ S. Karger AG, Basel
\end{abstract}




\section{Introduction}

Traditionally, the curative treatment of liver cancer has involved either surgical resection, liver transplantation [1], or local ablation, whereas transarterial tumor embolization has been used for palliative treatment [2]. Drug treatment for the more advanced stages of liver cancer has been attempted in the form of conventional chemotherapy in numerous usually uncontrolled clinical trials over the past 50 years [3], but neither doxorubicin nor any other of the traditionally used chemotherapy agents has given a survival advantage in a controlled clinical trial. In 2008, sorafenib was shown to improve overall survival in advanced-stage hepatocellular carcinoma (HCC) in a large prospective randomized controlled trial [4], and this improvement was confirmed in a second trial with similar design in an Asian population [5]. These two positive phase-III trials consequently led to the introduction of sorafenib as the standard of care for advanced-stage liver cancer. In the current European Association for the Study of the Liver (EASL) clinical practice guidelines on the management of liver cancer, the curative treatment options (resection, liver transplantation, and percutaneous ablation) are reserved for very early and early stage HCC patients with good performance status and reasonable liver function, whereas intermediate-stage tumors are treated by transarterial chemoembolization [6-8]. For advanced-stage patients with portal invasion, extrahepatic spread, or reduced performance status, sorafenib is the standard of care $[7,9]$.

\section{First-Line Treatment for Advanced-Stage HCC}

Sorafenib is a raf-, vascular endothelial growth factor (VEGF) receptor-, platelet-derived growth factor (PDGF) receptor-blocking multikinase tyrosine kinase inhibitor (TKI) [10]. After the initial publication of quite promising phase-II results for sorafenib in advancedstage liver cancer in 2006 [11], the results of two phase-III trials were eagerly awaited. In 2008 , the SHARP trial was finally published and showed a significant overall survival (OS) advantage in patients treated with sorafenib versus patients treated with placebo [10.7 versus 7.9 months, hazard ratio (HR) $0.69, \mathrm{p}<0.001]$. The trial was conducted in a mostly European patient cohort (including some US patients) with well-preserved liver function (Child A) and good performance status (PS0-2) but with either large intrahepatic tumors, tumors with vascular invasion, or with extrahepatic spread of HCC [4]. A little later, very similar data from the phase III Asia-Pacific study also reported a significant survival benefit with sorafenib versus placebo (HR $0.68, p=0.014$ ) in a study with the same inclusion criteria as the SHARP trial but, because of the confirmatory nature of the trial, with less than half the number of patients [5]. The OS in both arms of the Asia-Pacific study was shorter than that for the SHARP trial, i.e., 6.5 months in the sorafenib group and 4.5 months in the placebo group. Possible explanations for these absolute differences in survival between the two trials include a larger number of patients with extrahepatic spread in the Asia-Pacific study, with more advanced Eastern Cooperative Oncology Group (ECOG) performance status, the inclusion of patients with more than four tumor sites, and a larger number of patients with lung metastasis (50\% in the Asia-Pacific trial, 21\% in the SHARP trial). In addition, it cannot be ruled out that the Asian patients, mostly with Hepatitis B-associated HCC, in general show a more aggressive course of disease (and may well be detected at a later stage, as exemplified by the more advanced disease at inclusion into the Asia-Pacific trial). Nevertheless, the effect of sorafenib on OS was consistent between the two trials. Sorafenib also prolonged the time to progression (TTP), both in the SHARP trial (TTP: sorafenib 5.5 months versus placebo 2.8 months, $\mathrm{p}<0.001$ ) and in the Asia-Pacific trial (TTP: sorafenib 2.8 months versus placebo 1.4 months, $\mathrm{p}<0.001$ ). 
The most common adverse events were diarrhea (39\%) and hand-foot skin reaction (21\%), followed by anorexia and alopecia with both 14\% [4]. Nevertheless, most adverse events were of low grade (G1/2) and did not lead to discontinuation of the study drug. When looking at different subgroups of patients, it is important to know that sorafenib seems to work irrespective of the underlying disease etiology, any prior therapy received, or the pattern of vascular invasion or extrahepatic spread [12].

From the SHARP and the Asia-Pacific trials, because of the restrictive inclusion criteria, there is insufficient information about the effect of sorafenib in patients with more advanced liver disease (Child-Pugh B, Child-Pugh C) [13]. The first report on the survival outcome of patients with more advanced stage liver disease came from the real life Austrian cohort and showed that patients with Child B cirrhosis live about half as long as patients with Child A liver function (OS: Child A 11.3 months versus Child B 5.5 months). Well patients with Child C cirrhosis die very quickly despite sorafenib treatment (median OS 1.6 months) and they do not seem to be candidates for treatment with sorafenib [14]. These data were later confirmed by the large multinational phase IV observational study GIDEON, which included over 3000 patients with different degrees of liver function [15]. Unfortunately, no controlled data are available to indicate whether patients with Child B liver dysfunction are deriving a benefit from treatment with sorafenib, but at least one prospective randomized phase-III trial in Child B patients is currently ongoing to answer this question (BOOST, www.clinicaltrials.gov, NCT01405573).

In the absence of a prospective trial to answer this question, we looked at prognostic factors in the Austrian cohort to predict survival in patients with advanced-stage HCC and different degrees of liver dysfunction during sorafenib treatment. We were able to identify elevated aspartate aminotransferase (AST) levels as a very reliable and sensitive prognostic factor for patients undergoing sorafenib treatment [16]. Looking at the whole cohort with different degrees of liver dysfunction, AST $<100 \mathrm{IU} / \mathrm{L}$ indicated a median OS of 10.2 months, whereas AST $\geq 100 \mathrm{IU} / \mathrm{L}$ was associated with a median OS of only 2.7 months. The AST level remained a very strong and significant prognostic factor not only in Child A patients but also in the subgroup of Child B patients with advanced-stage HCC; in the latter group, the same cut-off for AST of $100 \mathrm{IU} / \mathrm{L}$ was able to distinguish between patients with a median OS of 6.5 months versus a median OS of 2.1 months. Thus, the AST level, which also is a very strong predictor for survival in intermediate-stage patients undergoing transarterial chemoembolization [17], is a simple, non-invasive, and accurate marker to rationally guide the use of sorafenib, particularly in resource-limited settings. Despite these data and the official recommendations in various international guidelines, foremost the EASL clinical practice guidelines [7], sorafenib is by far not the most commonly used treatment for patients with advanced-stage liver disease. As exemplified by the European data of the large worldwide observational BRIDGE study, sorafenib treatment accounts for only about $10 \%$ of the treatments used for advanced-stage HCC patients in Europe [18]. Most patients with advanced stage liver disease are not receiving medical treatment but all kinds of surgical to interventional treatments even in advanced stage HCC. If medical therapy is used in this patients, than at least in Europe and North America sorafenib is prescribed in over $90 \%$ of the patients, while in Asia only slightly more than $50 \%$ of patients are treated with sorafenib. A considerable number of patients receive other medical treatments, most of them chemotherapy-based [19].

\section{First-Line Treatments for HCC beyond Sorafenib}

The success of the TKI sorafenib for the treatment of HCC stimulated initiation of several clinical trials with similar drugs for this indication in prospective phase-III trials. The first to 
be completed was the first-line trial of sunitinib versus sorafenib, a randomized trial of 1074 patients comparing sunitinib $37.5 \mathrm{mg} /$ day versus sorafenib in standard dose ( $800 \mathrm{mg} /$ day). Since this trial was preceded by two phase-II trials with mixed results, it was not surprising to find that sunitinib was significantly worse in terms of OS than sorafenib was (median OS 7.9 versus 10.2 months, $p=0.014$ ] [20]. This difference was particularly pronounced in hepatitis-C-positive patients (median OS: sunitinib 9.2 versus sorafenib 17.6 months). Since the progression-free survival and the TTP were similar in both groups, the difference in OS results was most likely caused by the significantly higher toxicity of sunitinib in patients with HCC.

The next drug to be tested in a phase-III trial against sorafenib was brivanib, a VEGFreceptor-, fibroblast growth factor receptor-blocking multikinase TKI [21]. Again, in a large multinational phase-III trial involving 1155 patients, brivanib was unable to demonstrate non-inferiority to sorafenib (median OS brivanib 9.5 versus sorafenib 9.9 months; HR 1.07, $\mathrm{p}=0.3116$ ) [22]. Linifanib, a PDGF/VEGF-receptor TKI, also failed to show a survival advantage over sorafenib in a large phase-III trial (OS linifanib 9.1 versus sorafenib 9.1 months; $\mathrm{HR}=1.046)[23,24]$.

Attempting to combine sorafenib with another targeted agent has not been successful so far: when sorafenib was combined with the epidermal growth factor receptor-inhibitor erlotinib in the SEARCH phase-III trial, the combination of sorafenib and erlotinib (median OS 9.5 months) was not significantly better than sorafenib monotherapy (median OS 8.5 months; HR 0.929; $\mathrm{p}=0.204$ ) [25].

While still quite a few phase-III trials in the first-line setting for HCC are ongoing, testing drugs like Lenvatinib (www.clinicaltrials.gov; NCT01761266), a multikinase TKI inhibiting VEGFR2 and 3 [26], drug treatment for advanced stage HCC beyond sorafenib does not seem to be an easy target for drug development. Currently, a major search for informative biomarkers is taking place that should allow a more targeted approach in subgroups of patients with specific molecular profiles. That approach would allow to extend the survival of those patients by selective drug targeting beyond the survival achievable with sorafenib. Even though HCC is a heterogeneous tumor with different grades of differentiation within a single lesion and often considerable necrotic areas within a given tumor, this approach currently seems to be the most rational and promising [27]. It remains to be seen whether simple immunohistochemistry with a few markers or complex genetic analysis with microarray technology will yield informative results for drug development. But success without a rational approach seems unlikely.

\section{Second-Line Therapy for HCC}

Despite the significant improvement in OS with sorafenib, it only delays progression of the tumor (median TTP 5.5 months versus 2.8 months with placebo) [4]. This means that there is a great need for an active second-line treatment after progression with sorafenib. One obvious approach would be to continue sorafenib despite progression, but no definitive data are currently available as to whether this approach would be of any use. In particular, in the SHARP trial it was left to the discretion of the investigator what to do after progression. Some investigators continued sorafenib while others discontinued it. No conclusion can therefore be drawn from the SHARP study regarding what to do after progression. Another approach that works in kidney cancer would be to increase the dose of sorafenib with progression, but the only study available so far has too few patients enrolled for any relevant conclusion to be drawn and does not show a difference in median progression-free survival, 
which might not have much relevance for median OS [28]. Another line of attack taken by several pharmaceutical companies was to test targeted agents with slightly different molecular profiles than sorafenib. The first second-line phase-III trial to be reported was the BRISKPS (brivanib-post sorafenib) trial, which was not able to show any improvement in median OS with brivanib compared to best supportive care plus placebo (median OS: brivanib 9.4 months versus placebo 8.2 months; HR 0.89, p=0.3307) [29]. The results of this trial were surprising and disappointing at the same time, but even when looking at detailed subgroup analyses, brivanib did not seem to offer a survival benefit in any of the subgroups analyzed: neither according to geographic region, nor to etiology of liver disease, nor to ECOG performance status, nor to tumor distribution, nor to tumor size. The second phase-III trial in a second-line setting to be reported was the EVOLVE-1 trial. Here, everolimus, an mTOR inhibitor, was tested at a daily dose of $7.5 \mathrm{mg}$ versus placebo but was able to show only a modest benefit in median OS (everolimus 7.6 months versus placebo 7.3 months; HR 1.05, p=0.675) [30]. In this study, there was no benefit in the median TTP, or in the overall population, or in any of the pre-stratified subgroups. Only the disease control rate was significantly better in the everolimus group, which has little meaning for the overall evaluation of the results. The ongoing REACH phase-III trial is testing the monoclonal anti-VEGFR2 antibody ramucirumab in the second-line setting for HCC after sorafenib failure. Judging from the first-line phase-II data, this antibody, which is used intravenously at a dose of $8 \mathrm{mg} / \mathrm{kg}$ every 2 weeks, could have significant effects on overall survival of patients with advanced-stage HCC [31].

Another oral multikinase inhibitor, which is currently in phase-III development, is regorafenib, a raf-, VEGF-, PDGF-, Tie2-inhibitor [32]. Because regorafenib has a similar but more extended target range and a more potent action compared to sorafenib, this drug is tested only in patients with progression under sorafenib but not in those with intolerance to sorafenib.

A current focus of interest for HCC drug development is the c-met inhibitor tivantinib. In early gene array studies, it was demonstrated that elevated expression of c-met was associated with poor outcome and short overall survival in patients with liver cancer [33]. In a highly publicized phase-II trial, tivantinib was able to significantly improve overall survival in patients with high c-met expression in the tumor tissue, whereas it had no effect on median OS in patients with low expression of c-met [34]. In the two currently ongoing phase-III trials (www.clinicaltrials.gov, NCT01755767 for the European/US trial, NCT02029157 for the Japanese trial), tivantinib is being tested in patients with sorafenib failure against best supportive care and placebo. Despite initial problems with severe neutropenia in the European/US trial due to a change in the drug formulation used in the phase-III as compared to the phase-II trial, this study is currently ongoing and is actively recruiting patients.

Besides tivantinib, other c-met inhibitors are undergoing clinical testing, e.g., cabozantinib [35] in a second-line phase-III trial (www.clinicaltrials.gov; NCT01908426) and Inc-280 in a first-line phase-II trial (www.clinicaltrials.gov; NCT01737827). A similarly targeted approach is being taken with the MEK-inhibitor refametinib [36] in Ras-mutated HCC in two single-arm phase-II trials (www.clinicaltrials.gov; first line combined with sorafenib: NCT01915602, and second line versus placebo: NCT01915589). Refametinib is a very interesting compound, albeit with potential application to only a small subgroup of HCC-patients.

\section{Future Prospects}

Even though many drug companies are taking a more cautious approach after the failure of several phase-III trials for first- and even second-line treatment of advanced-stage and even earlier stage liver cancer, there is still great hope for a further step forward in the medi- 
cal treatment of HCC [37]. The more targeted, tumor biology-driven approaches now being taken, together with careful clinical trial design [38], will offer a greater chance for success than in the past. Nevertheless, much more basic research on HCC tumor biology is needed in order to be successful in a third and fourth wave of drug development for a difficult to treat tumor such as liver cancer, even in patients with well-preserved liver function.

\section{References}

1 Belghiti J, Fuks D: Liver resection and transplantation in hepatocellular carcinoma. Liver Cancer 2012;1:71-82.

2 Llovet JM, Brú C, Bruix J: Prognosis of hepatocellular carcinoma: the BCLC staging classification. Semin Liver Dis 1999;19:329-338.

-3 Thomas MB, O’Beirne JP, Furuse J, Chan AT, Abou-Alfa G, Johnson P: Systemic therapy for hepatocellular carcinoma: cytotoxic chemotherapy, targeted therapy and immunotherapy. Ann Surg Oncol 2008;15:1008-1014.

4 Llovet JM, Ricci S, Mazzaferro V, Hilgard P, Gane E, Blanc JF, de Oliveira AC, Santoro A, Raoul JL, Forner A, Schwartz M, Porta C, Zeuzem S, Bolondi L, Greten TF, Galle PR, Seitz JF, Borbath I, Häussinger D, Giannaris T, Shan M, Moscovici M, Voliotis D, Bruix J, SHARP Investigators Study Group: Sorafenib in advanced hepatocellular carcinoma. N Engl J Med 2008;359:378-390.

5 Cheng AL, Kang YK, Chen Z, Tsao CJ, Qin S, Kim JS, Luo R, Feng J, Ye S, Yang TS, Xu J, Sun Y, Liang H, Liu J, Wang J, Tak WY, Pan H, Burock K, Zou J, Voliotis D, Guan Z: Efficacy and safety of sorafenib in patients in the Asia-Pacific region with advanced hepatocellular carcinoma: a phase III randomised, double-blind, placebo-controlled trial. Lancet Oncol 2009;10:25-34.

6 Lencioni R: Chemoembolization in patients with hepatocellular carcinoma. Liver Cancer 2012;1:41-50.

-7 European Association For The Study Of The Liver European Organisation For Research And Treatment Of Cancer: EASL-EORTC clinical practice guidelines: management of hepatocellular carcinoma. J Hepatol 2012;56:908-943.

-8 Peck-Radosavljevic M, Sieghart W, Kölblinger C, Reiter M, Schindl M, Ulbrich G, Steininger R, Müller C, Stauber R, Schöniger-Hekele M, Gschwendtner M, Plank C, Funovics M, Graziadei I, Lammer J, Gruenberger T, Gastl G, Karnel F, Austrian Association of Gastroenterology,Hepatology (ÖGGH) Austrian Society of Interventional Radiology (ÖGIR) Austrian Society of Hematology and Oncology (ÖGHO) Austrian Society for Surgical Oncology (ASSO): Austrian Joint ÖGGH-ÖGIR-ÖGHO-ASSO position statement on the use of transarterial chemoembolization (TACE) in hepatocellular carcinoma. Wien Klin Wochenschr 2012;124:104110.

-9 Kudo M: Treatment of advanced hepatocellular carcinoma with emphasis on hepatic arterial infusion chemotherapy and molecular targeted therapy. Liver Cancer 2012;1:62-70.

10 Wilhelm SM, Adnane L, Newell P, Villanueva A, Llovet JM, Lynch M: Preclinical overview of sorafenib, a multikinase inhibitor that targets both Raf and VEGF and PDGF receptor tyrosine kinase signaling. Mol Cancer Ther 2008;7:3129-3140.

$\checkmark 11$ Abou-Alfa GK, Schwartz L, Ricci S, Amadori D, Santoro A, Figer A, De Greve J, Douillard JY, Lathia C, Schwartz B, Taylor I, Moscovici M, Saltz LB: Phase II study of sorafenib in patients with advanced hepatocellular carcinoma. J Clin Oncol 2006;24:4293-4300.

12 Bruix J, Raoul JL, Sherman M, Mazzaferro V, Bolondi L, Craxi A, Galle PR, Santoro A, Beaugrand M, Sangiovanni A, Porta C, Gerken G, Marrero JA, Nadel A, Shan M, Moscovici M, Voliotis D, Llovet JM: Efficacy and safety of sorafenib in patients with advanced hepatocellular carcinoma: subanalyses of a phase III trial. J Hepatol 2012;57:821-829.

13 Peck-Radosavljevic M, Greten TF, Lammer J, Rosmorduc O, Sangro B, Santoro A, Bolondi L: Consensus on the current use of sorafenib for the treatment of hepatocellular carcinoma. Eur J Gastroenterol Hepatol 2010;22:391-398.

14 Pinter M, Sieghart W, Graziadei I, Vogel W, Maieron A, Königsberg R, Weissmann A, Kornek G, Plank C, Peck-Radosavljevic M: Sorafenib in unresectable hepatocellular carcinoma from mild to advanced stage liver cirrhosis. Oncologist 2009;14:70-76.

15 Marrero JA, Lencioni R, Ye SL, Kudo M, Bronowicki JP, Chen XP, et al: Final analysis of GIDEON (Global Investigation of Therapeutic Decisions in Hepatocellular Carcinoma and of Its Treatment with Sorafenib) in >3000 Sor-treated patients: Clinical findings in patients s with liver dysfunction. J Clin Oncol 2013;31(Suppl.):A4126.

16 Pinter M, Sieghart W, Hucke F, Graziadei I, Vogel W, Maieron A, Königsberg R, Weissmann A, Kornek G, Matejka J, Stauber R, Buder R, Grünberger B, Schöniger-Hekele M, Müller C, Peck-Radosavljevic M: Prognostic factors in patients with advanced hepatocellular carcinoma treated with sorafenib. Aliment Pharmacol Ther 2011;34:949-959.

-17 Sieghart W, Hucke F, Pinter M, Graziadei I, Vogel W, Müller C, Heinzl H, Trauner M, Peck-Radosavljevic M: The ART of decision making: retreatment with transarterial chemoembolization in patients with hepatocellular carcinoma. Hepatology 2013;57:2261-2273. 
18 Izzo F, Colombo M, Leroy V, Blanc JF, Johnson P, Fenwick S, et al: Observations of hepatocellular carcinoma (HCC) management patterns from the global HCC BRIDGE study: second interim analysis of the European (EU) cohort. J Hepatol 2012;56(Suppl.2):S284.

19 Colombo M, Roberts L, Schwartz M, Degos F, Sherman M, Chen PJ, et al: Observed patterns of systemic therapy use in hepatocellular carcinoma (HCC) patients from the multinational HCC BRIDGE study: results of a second interim analysis. J Hepatol 2012;56(Suppl.2):S276-S277.

20 Cheng AL, Kang YK, Lin DY, Park JW, Kudo M, Qin S, Chung HC, Song X, Xu J, Poggi G, Omata M, Pitman Lowenthal S, Lanzalone S, Yang L, Lechuga MJ, Raymond E: Sunitinib versus sorafenib in advanced hepatocellular cancer: results of a randomized phase III trial. J Clin Oncol 2013;31:4067-4075.

-21 Huynh H, Ngo VC, Fargnoli J, Ayers M, Soo KC, Koong HN, Thng CH, Ong HS, Chung A, Chow P, Pollock P, Byron $S$, Tran E: Brivanib alaninate, a dual inhibitor of vascular endothelial grow th factor receptor and fibroblast growth factor receptor tyrosine kinases, induces growth inhibition in mouse models of human hepatocellular carcinoma. Clin Cancer Res 2008;14:6146-6153.

-22 Johnson PJ, Qin S, Park JW, Poon RT, Raoul JL, Philip PA, Hsu CH, Hu TH, Heo J, Xu J, Lu L, Chao Y, Boucher E, Han KH, Paik SW, Robles-Aviña J, Kudo M, Yan L, Sobhonslidsuk A, Komov D, Decaens T, Tak WY, Jeng LB, Liu D, Ezzeddine R, Walters I, Cheng AL: Brivanib versus sorafenib as first-line therapy in patients with unresectable, advanced hepatocellular carcinoma: results from the randomized phase III BRISK-FL study. J Clin Oncol 2013;31:3517-3524.

23 Cainap C, Qin S, Huang WT, Chung IJ, Pan H, Cheng Y, et al: Phase III trial of linifanib versus sorafenib in patients with advanced hepatocellular carcinoma (HCC). J Clin Oncol 2012;30(Suppl 34):A249.

24 Kudo M: Why does every hepatocellular carcinoma clinical trial using molecular targeted agents fail? Liver Cancer 2012;1:59-60.

25 Zhu AX, Rosmorduc O, Evans J, Ross P, Santoro A, Carrilho FJ, et al: Search: a phase III, randomized, doubleblind, placebo-controlled trial of sorafenib plus erlotinib in patients with hepatocellular carcinoma (HCC). Ann Oncol 2012;23(Suppl 9):A917.

26 Inoue K, Asai N, Mizuo H, Fukuda K, Kusano K, Yoshimura T: Unique metabolic pathway of [(14)C]lenvatinib after oral administration to male cynomolgus monkey. Drug Metab Dispos 2012;40:662-670.

-27 Schirmacher P, Bedossa P, Roskams T, Tiniakos DG, Brunt EM, Zucman-Rossi J, Manns MP, Galle PR: Fighting the bushfire in HCC trials. J Hepatol 2011;55:276-277.

28 Rimassa L, Pressiani T, Boni C, Carnaghi C, Rota Caremoli E, Fagiuoli S, Foa P, Salvagni S, Cortesi E, Chiara Tronconi M, Personeni N, Bozzarelli S, Chiara Banzi M, Fanello S, Romano Lutman F, Giordano L, Santoro A: A phase II randomized dose escalation trial of sorafenib in patients with advanced hepatocellular carcinoma. Oncologist 2013;18:379-380.

29 Llovet JM, Decaens T, Raoul JL, Boucher E, Kudo M, Chang C, Kang YK, Assenat E, Lim HY, Boige V, Mathurin P, Fartoux L, Lin DY, Bruix J, Poon RT, Sherman M, Blanc JF, Finn RS, Tak WY, Chao Y, Ezzeddine R, Liu D, Walters I, Park JW: Brivanib in patients with advanced hepatocellular carcinoma who were intolerant to sorafenib or for whom sorafenib failed: results from the randomized phase III BRISK-PS study. J Clin Oncol 2013;31:3509-3516.

30 .Zhu AX, Kudo M, Assenat E, Cattan S, Kang Y-KL, Ho Yeong, Poon RT, et al. EVOLVE-1: Phase 3 study of everolimus for advanced HCC that progressed during or after sorafenib. J Clin Oncol. 2014: ASCO-GI.

-31 Zhu AX, Finn RS, Mulcahy M, Gurtler J, Sun W, Schwartz JD, Dalal RP, Joshi A, Hozak RR, Xu Y, Ancukiewicz M, Jain RK, Nugent FW, Duda DG, Stuart K: A phase II and biomarker study of ramucirumab, a human monoclonal antibody targeting the VEGF receptor-2, as first-line monotherapy in patients with advanced hepatocellular cancer. Clin Cancer Res 2013;19:6614-6623.

-32 Bruix J, Tak WY, Gasbarrini A, Santoro A, Colombo M, Lim HY, Mazzaferro V, Wiest R, Reig M, Wagner A, Bolondi L: Regorafenib as second-line therapy for intermediate or advanced hepatocellular carcinoma: multicentre, open-label, phase II safety study. Eur J Cancer 2013;49:3412-3419.

-33 Kaposi-Novak P, Lee JS, Gòmez-Quiroz L, Coulouarn C, Factor VM, Thorgeirsson SS: Met-regulated expression signature defines a subset of human hepatocellular carcinomas with poor prognosis and aggressive phenotype. J Clin Invest 2006;116:1582-1595.

34 Santoro A, Rimassa L, Borbath I, Daniele B, Salvagni S, Van Laethem JL, Van Vlierberghe H, Trojan J, Kolligs FT, Weiss A, Miles S, Gasbarrini A, Lencioni M, Cicalese L, Sherman M, Gridelli C, Buggisch P, Gerken G, Schmid RM, Boni C, Personeni N, Hassoun Z, Abbadessa G, Schwartz B, Von Roemeling R, Lamar ME, Chen Y, Porta C: Tivantinib for second-line treatment of advanced hepatocellular carcinoma: a randomised, placebo-controlled phase 2 study. Lancet Oncol 2013;14:55-63.

-35 Xiang Q, Zhang D, Wang J, Zhang H, Zheng Z, Yu D, Li Y, Xu J, Chen Y, Shang C: Cabozantinib reverses multidrug resistance of human hepatoma HepG2/adr cells by modulating the function of P-glycoprotein. Liver Int 2014;Doi:.10.1111/liv.12524,(in press).

-36 Schmieder R, Puehler F, Neuhaus R, Kissel M, Adjei AA, Miner JN, Mumberg D, Ziegelbauer K, Scholz A: Allosteric MEK1/2 inhibitor refametinib (BAY 86-9766) in combination with sorafenib exhibits antitumor activity in preclinical murine and rat models of hepatocellular carcinoma. Neoplasia 2013;15:1161-1171.

37 Shen YC, Lin ZZ, Hsu CH, Hsu C, Shao YY, Cheng AL: Clinical trials in hepatocellular carcinoma: an update. Liver Cancer 2013;2:345-364.

-38 Llovet JM, Di Bisceglie AM, Bruix J, Kramer BS, Lencioni R, Zhu AX, Sherman M, Schwartz M, Lotze M, Talwalkar J, Gores GJ, Panel of Experts in HCC-Design Clinical Trials: Design and endpoints of clinical trials in hepatocellular carcinoma. J Natl Cancer Inst 2008;100:698-711. 